\section{Physiological Curve of Response to Plant Growth Hormones}

THE addition of growth hormones to a variety of plant materials results in marked responses over appropriate concentration ranges. The behaviour

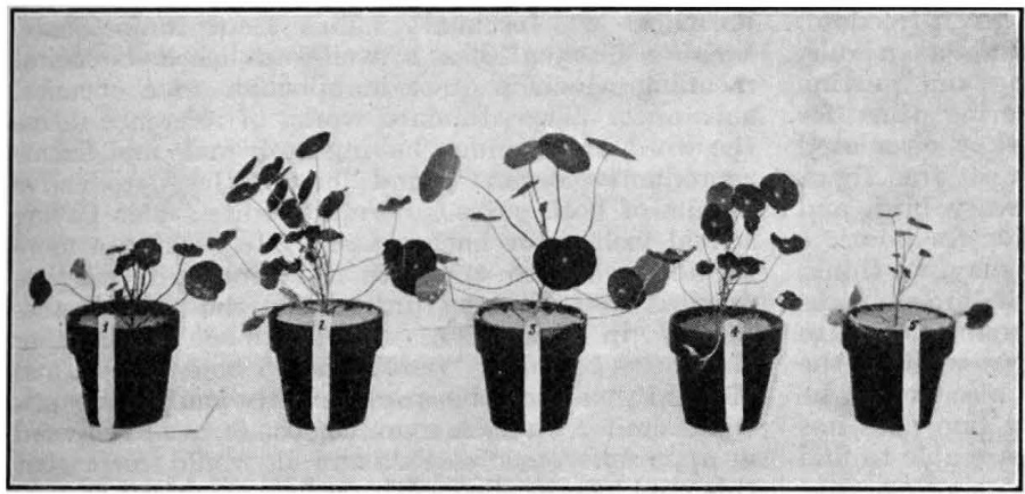

EFFECT OF GROWTH HORMONE ON NASTURTIUMS. LEFT TO RIGHT : 50 C.c. DAILY NUTRIENT SOLUTION ONLY; SAME, CONTAINING $1 / 100,1 / 10,1$ AND 2.5 P.P.M. I-NAPHTHYLACETIC ACID RESPECTIVELY.

varies with the particular hormone used, the method of application and the developmental stage of the plant. With graded concentrations of growth hormone the response assumes the form of a physiological curve.

The accompanying photograph shows the characteristic curve obtained with nasturtiums. After fourteen days growth in soil, these plants were transferred to sand in 4-in. pots and treated for twenty-three days in the manner indicated. Marked stimulation in growth at low concentrations is followed by damage as the amount of growth hormone is increased to excess. A physiological curve of this sort is known to be characteristic of the responses which are obtained with a number of different plants, including certain lower plant forms, such as yeast.

Marked increase in the rate of growth is obtained by the addition to the soil of exceedingly small quantities of the active chemicals. The green weight of tops of 8-weeks old lettuce plants was increased more than 300 per cent by the addition of the equiva. lent of $150 \mathrm{mgm}$. of 1-napthylacetic acid to an acre. This particular result was obtained by applying appropriate quantities of 1/100 p.p.m. solution at intervals of three days.

The dusting of seeds with growth hormones incorporated in a suitable diluent carrier caused substantial increases in both top and root development. This method of application is particularly advan. tageous, as it supplies the active chemicals gradually, and avoids the inhibition of root growth which usually results from a solution method of treatment.

A paper on this subject will appear shortly in the Canadian Journal of Research.

\section{N. H. GRACE.}

Division of Biology and Agriculture, National Research Laboratories, Ottawa.

Nov. 19.

\section{Experiments on Homing in Birds}

EXPERIMENTS on homing in birds were made by one of us ${ }^{1}$ for the first time in 1933. These showed that wild birds, especially swallows, have more sense of orientation and are better able to find their homes than even carrier pigeons. Later on, Rüppell ${ }^{2}$ established as a result of a series of experiments that swallows could find their homes from distances as great as 1,850 $\mathrm{km}$. The same applies to starlings and wrynecks.

This year we experimented on white storks for the first time. In one test they were taken $50 \mathrm{~km}$. and $111 \mathrm{~km}$. away from Butyny, near Lwów ; in another series of tests the birds were transported by aeroplanes (Polish Airways "L.D.T.") from Butyny to Warsaw, Bukarest and Lydda in Palestine, $300 \mathrm{~km}$., $660 \mathrm{~km}$. and $2,260 \mathrm{~km}$. respectively. These distances are all along the airline shown in the map below. The birds were specially marked in bright colours and also ringed, so that it was comparatively easy to recognize them after their return to their nests and young.

The results confirmed that 75 per cent of the birds tested came home safely. The average speed of their journey was one third slower than the speed of swallows over small distances, although it equalled

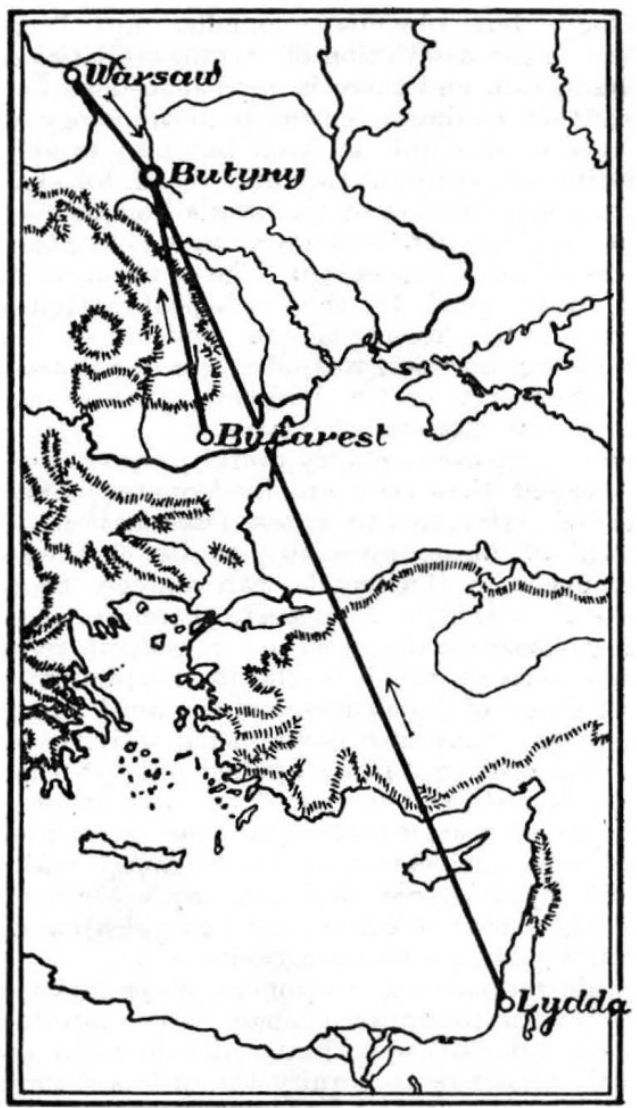

